\title{
PERANCANGAN DUAL INPUT KONVERTER ARUS SEARAH TIPE ZETA BERBASIS MICROCONTROLLER ARDUINO
}

\author{
Atma Karyadi*), Trias Andromeda dan Yuli Christyono \\ Departemen Teknik Elektro, Universitas Diponegoro Semarang \\ J1. Prof. Sudharto, SH, Kampus UNDIP Tembalang, Semarang 50275, Indonesia \\ ${ }^{*}$ E-mail: atmkary@gmail.com
}

\begin{abstract}
Abstrak
Dewasa ini kebutuhan konversi tegangan arus searah yang berasal dari energi baru terbarukan semakin banyak digunakan terutama dalam skala rumah tangga. Salah satu cara untuk mengkonversi tegangan arus searah konstan ke tegangan arus searah yang dapat divariasikan adalah dengan menggunakan dual input konverter arus searah tipe Zeta. Penggunaan rangkaian dual input konverter arus searah untuk pengisian baterai sudah mulai berkembang. Proses pengisian baterai perlu memperhatikan nilai arus dan tegangan yang mengalir ke baterai. Arus dan tegangan yang tidak sesuai dapat merusak baterai dan mengurangi umur baterai. Hal tersebut dapat diatasi dengan menggunakan metode umpan balik arus dan tegangan sehingga proses pengisian baterai menggunakan konverter arus searah dapat bersifat loop tertutup. Berdasarkan hasil pengukuran, rangkaian dual input konverter arus searah tipe Zeta dengan umpan balik arus mampu menjaga arus keluaran konverter arus searah tipe Zeta pada 0,25 A. Sementara saat umpan balik tegangan, nilai tegangan keluaran dapat dijaga pada nilai 14,4 volt dan 13,5 volt dengan nilai efisiensi rata-rata konverter arus searah tipe Zeta sebesar $83,74 \%$ dengan umpan balik tegangan.
\end{abstract}

Kata kunci: Dual input konverter, Konverter arus searah Zeta, Umpan balik, Pengisian akumulator

\begin{abstract}
In this era, the need of direct current power supply from renewable energy is increasingly being used, especially in the household scale. One way to convert a DC voltage constant to DC voltage that can be varied is to use a dual inputs Zeta converter. The usage of a dual input DC converter for battery charging has begun to develop. The battery charging process needs to keep the current and voltage values that flow to the battery. Improper currents and voltages can damage the battery and reduce the usage time. This can be overcome by using the current and voltage feedback methods so that the battery charging process using DC converter can be closed loop. Based on the measurement results, the dual imputs Zeta converter is able to maintain the output current of the Zeta converter at $0.25 \mathrm{~A}$. While the voltage feedback, the output voltage can be maintained at a value of 14.4 volts and 13,5 volts with an average Zeta's efficiency value of $83.74 \%$ with voltage feedback.
\end{abstract}

Keywords: Dual inputs converter, Zeta converter, Feedback, Accumulator charge

\section{Pendahuluan}

Pemanfaatan energi baru terbarukan dalam rangka mewujudkan kemandirian dan ketahanan energi semakin banyak berkembang. Menurut Blueprint Pengelolaan Energi Nasional (BP-PEN) yang dikeluarkan oleh Kementerian ESDM menyebutkan bahwa sasaran penggunaan energi baru terbarukan diharapkan dapat meningkat sebesar 5\% di tahun 2025[1]. Untuk menunjang target tersebut, maka diperlukan perkembangan teknologi konverter arus searah yang mampu mengubah tingkat tegangan dari sumber energi baru terbarukan menjadi tingkat tegangan yang diinginkan.
Salah satunya adalah pengembangan konverter arus searah tipe Zeta yang mampu mengkonversi tegangan arus searah menjadi lebih tinggi atau lebih rendah[2]. Sama seperti tipe konverter arus searah lainnya, konverter arus searah tipe Zeta beroperasi dengan mode pensaklaran yang diatur dengan menggunakan Pulse Width Modulation (PWM). Pengaturan PWM akan memicu besarnya lebar pulsa (dutycycle) PWM yang menentukan mode pensaklaran yang sedang berlangsung dalam konverter arus searah tersebut. Pada penelitian [3], dibahas konverter arus searah Zeta yang dilengkapi power factor correction untuk mengatur kecepatan motor BLDC. Pada penelitian [4], dibahas perancangan konverter arus searah tipe Zeta dengan umpan balik tegangan. Pada penelitian [5], dibahas mengenai kinerja konverter arus 
searah Buck dengan umpan balik tegangan dan arus menggunakan microcontroller Arduino.

Pada Penelitian ini dirancang rangkaian dual input konverter arus searah Zeta berbasis microcontroller Arduino. Penelitian ini mengimplementasikan fitur pengontrol tegangan pada microcontroller Arduino untuk mengendalikan tegangan keluaran konverter arus searah Zeta yang akan mengisi baterai. Duty cycle yang dihasilkan microcontroller Arduino akan berubah secara otomatis ketika menerima sinyal umpan balik (feedback). Proses ini akan menyebabkan tegangan keluaran konverter arus searah Zeta secara otomatis menyesuaikan tegangan referensi. Beban yang digunakan pada Penelitian ini adalah baterai yang nantinya akan menjadi sumber daya keseluruhan sistem dalam Hybrid Charger Controller.

\section{Metode}

\subsection{Perancangan Perangkat Keras}

Perancangan Penelitian ini terdiri dari rangkaian penyearah, rangkaian konverter arus searah Zeta, dan rangkaian pembangkit sinyal PWM sesuai dengan blok diagram pada Gambar 1. berikut.

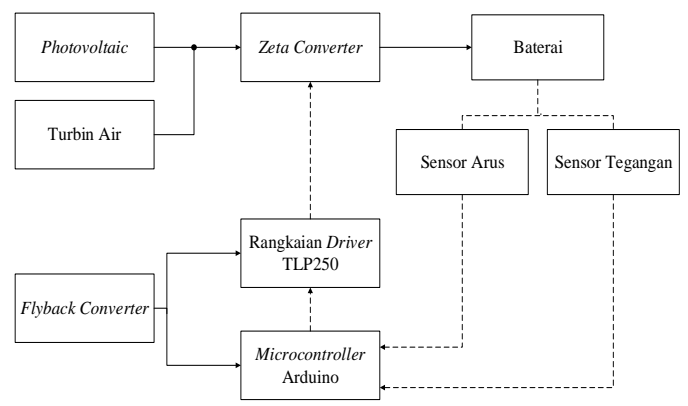

Gambar 1. Blok Diagram Alat

\subsection{Dual Input Konverter Arus Searah Zeta}

Berikut merupakan rangkaian dual input konverter arus searah tipe Zeta seperti yang tersaji pada Gambar 2. di bawah ini.

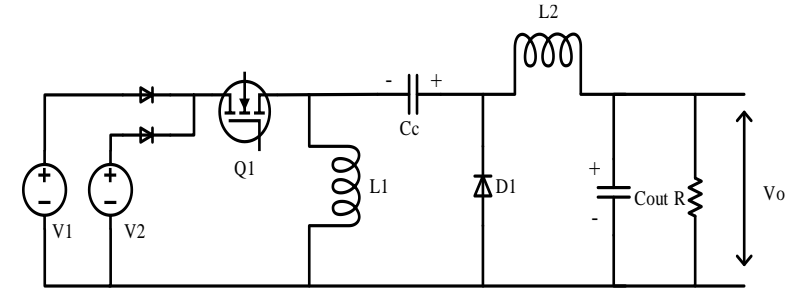

\section{Gambar 2. Rangkaian Dual Input Konverter Arus Searah Zeta}

Rangkaian dual input konverter arus searah Zeta tersusun dari komponen-komponen berikut:
1. Dua Sumber Tegangan DC $\left(V_{i n}\right)$

Sumber tegangan yang digunakan sebagai suplai daya konverter berasal dari dua sumber energi terbarukan. Dioda blocking pada masukan bertujuan untuk mencegah adanya arus balik yang berasal dari sumber tegangan yang lebih tinggi menuju sumber tegangan yang lebih rendah[6].

2. Saklar

MOSFET yang digunakan adalah MOSFET IRFZ 44N yang mempunyai tegangan Drain-Source sebesar $55 \mathrm{~V}$ dan kemampuan arus drain maksimal 49A[7], sehingga pemakaian MOSFET tipe IRFZ 44N ini aman untuk dipakai karena arus rata-rata yang dialirkan rangkaian daya yaitu $0,25 \mathrm{~A}$

3. Dioda

Dioda yang digunakan adalah SR5100. . Dioda SR5100 merupakan dioda schottky yang memiliki kemampuan menghantarkan arus sampai 5A dan tegangan sebesar 70V[8]

4. Induktor

Induktor yang digunakan pada konverter arus searah ini diperhitungkan nilainya untuk disesuaikan dengan parameter lain yang berhubungan. Induktor yang digunakan merupakan induktor jenis solenoida yang dibuat dari kawat tembaga yang dililitkan pada inti ferit.

$$
\begin{aligned}
& L_{1}=\frac{V_{i n} \cdot D}{\Delta I_{L 1} \cdot f_{s}} \\
& L_{1}=\frac{18 \times 0,434}{0.3 \times 62500} \\
& L_{1}=0,4167 \mathrm{mH}
\end{aligned}
$$

Jadi dari perhitungan diatas maka dipilih induktor L1 dengan nilai $0,87 \mathrm{mH}$. Pemilihan nilai induktor lebih besar dari nilai induktor minimal agar Konverter arus searah Zeta bekerja pada Continous Conduction Mode (CCM).

$$
\begin{aligned}
& L_{2}=\frac{V_{i n} \cdot D}{\Delta I_{L 2} \cdot f_{s}} \\
& L_{2}=\frac{18 \times 0,434}{0.3 \times 62500} \\
& L_{2}=0,4167 \mathrm{mH}
\end{aligned}
$$

Jadi dari perhitungan diatas maka dipilih induktor L2 dengan nilai $0,56 \mathrm{mH}$. Pemilihan nilai induktor lebih besar dari nilai induktor minimal agar Konverter arus searah Zeta memilik ripple arus yang lebih kecil dari perhitungan.

5. Kapasitor

Kapasitor Cc berfungsi sebagai kapasitor coupled sedangkan kapasitor Cout berfungsi sebagai filter tegangan untuk membatasi ripple tegangan yang disebabkan kenaikan nilai beban. 


$$
\begin{aligned}
& C_{c}=\frac{D . I_{\text {out }}}{\Delta V_{\text {ce }} f s} \\
& C_{c}=\frac{0,434 \times 0,5}{0,2 \times 62500}=17,63 \mu F
\end{aligned}
$$

Realisasinya kapasitor yang dipasang adalah $220 \mu \mathrm{F}$.

Sedangkan untuk menentukan nilai kapasitor keluaran (Cout).

$$
\begin{aligned}
C_{\text {out }} & =\frac{\Delta I_{L 2}}{8 . \Delta V_{\text {cout }} f s} \\
C_{\text {out }} & =\frac{0,3}{8 \times 0,01 \times 62500} \\
C_{\text {out }} & =60 \mu F
\end{aligned}
$$

Realisasinya kapasitor yang dipasang sebesar $220 \mu \mathrm{F}$ agar keluaran ripple tegangan keluaran Zeta konverter kecil.

\subsection{Rangkaian Kontrol}

Pada Penelitian ini akan digunakan microcontroller Arduino Nano.Untuk pembacaan arus pada baterai akan menggunakan sensor arus ACS712 sedangkan untuk pembacaan tegangan akan menggunakan rangkaian pembagi tegangan.

\section{Sensor Arus}

Sensor arus yang digunakan dalam sistem ini adalah sensor arus ACS712. Sensor ACS712 bekerja menggunakan prinsip Hall Effect yang mana arus yang mengalir akan menghasilkan medan magnet. Medan magnet tersebut diterima integrated hall IC dan kemudian diubah menjadi tegangan proporsional.

2.Sensor Tegangan

Dalam realisasi alat digunakan rangkaian pembagi tegangan untuk membaca tegangan yang ingin dibaca. Sensor tegangan bekerja dengan cara menurunkan nilai tegangan input dan dibagi menggunakan dua buah resistor.

3.Microcontroller Arduino

Pada Penelitian ini digunakan microcontroller Arduino Nano sebagai penghasil nilai PWM.

\subsection{Rangkaian MOSFET driver TLP250}

Rangkaian MOSFET driver TLP250 digunakan sebagai penguat sinyal keluaran PWM microcontroller menuju rangkaian dual input konverter arus searah Zeta. Pada Gambar 3. tersaji gambar rangkaian MOSFET Driver TLP250 sebagai berikut:

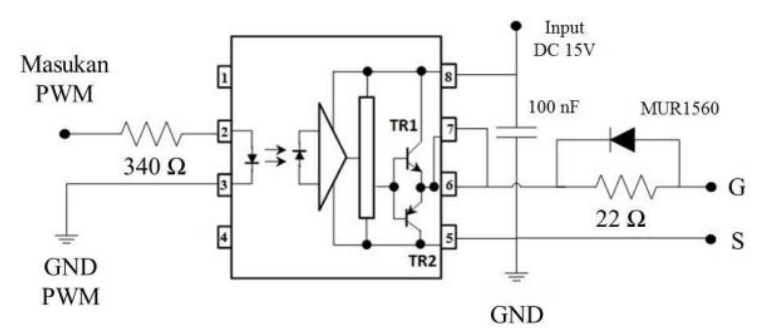

Gambar 3. Rangkaian MOSFET driver TLP250

Pada Gambar 3, TLP250 mendapat suplai Vcc $15 \mathrm{~V}$ berasal dari rangkaian konverter arus searah Flyback. Pada rangkaian TLP250 juga terdapat kapasitor bypass $100 \mathrm{nF}$ antara power supply IC dengan ground output. Resistor $22 \Omega$ yang terhubung pin 6 dan 7 menuju gate MOSFET berfungsi sebagai pembatas arus sinyal keluaran TLP250[9].

\subsection{Beban Pengujian}

Pengujian rangkaian dual input konverter Zeta menggunakan dua macam beban, yaitu beban resistor dan akumulator. Akumulator yang digunakan adalah akumulator Panasonic dengan tegangan nominal sebesar 12 volt dan kapasitas 7,2Ah/10Hr.

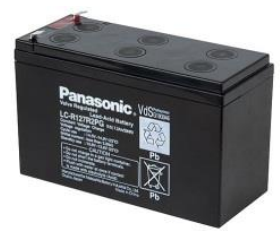

\section{Gambar 4. Akumulator}

\section{Hasil dan Analisis}

\subsection{Pengujian Rangkaian Kontrol}

3.1.1. Pengujian PWM Arduino Nano

Pada Gambar 5 ditunjukkan output pin PWM pada nilai duty cycle $50 \%$ dengan $\mathrm{t} / \mathrm{div}=10 \mu \mathrm{s}$ dan $\mathrm{V} / \mathrm{div}=5 \mathrm{~V}$. Level tegangan yang dihasilkan Arduino Nano adalah 5 volt.

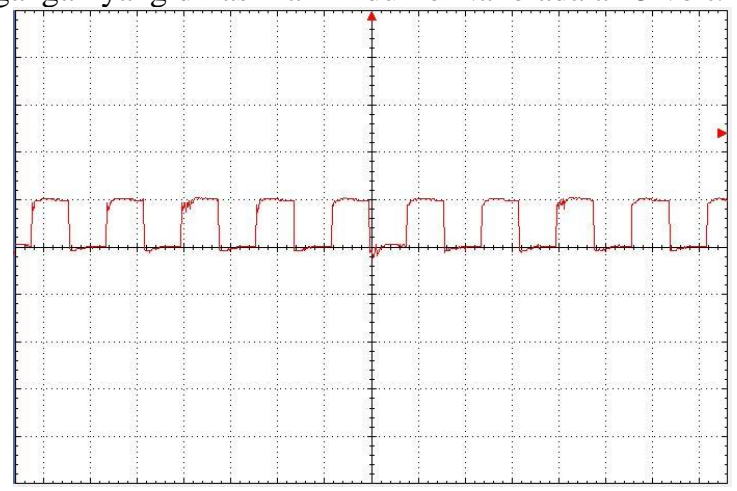

Gambar 5. Gelombang PWM pin 6 Arduino Nano dengan duty cycle $50 \%$ 


\subsubsection{Pengujian Rangkaian MOSFET Driver TLP250}

Pada Gambar 6 ditunjukkan output TLP250 pada nilai duty cycle $50 \%$ dengan $\mathrm{t} / \mathrm{div}=10 \mu \mathrm{s}$ dan $\mathrm{V} / \mathrm{div}=5 \mathrm{~V}$. Level tegangan yang dihasilkan Arduino Nano adalah 15 volt sehingga cukup untuk memicu MOSFET IRFZ44N..

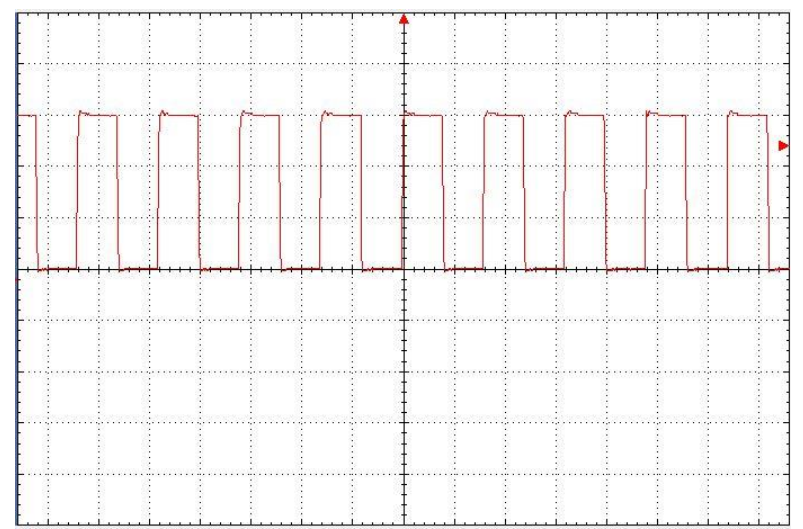

Gambar 6. Gelombang PWM pin 6 Arduino Nano dengan duty cycle $\mathbf{5 0 \%}$

\subsubsection{Pengujian Sensor Tegangan}

Tujuan dari pengujian sensor tegangan adalah untuk membandingkan hasil pembacaan sensor tegangan hasil perancangan dengan hasil pembacaan tegangan menggunakan Multimeter Sanwa CD800a

Tabel 1. Perbandingan tegangan hasil pengukuran dengan tegangan sensor

\begin{tabular}{cccc}
\hline $\begin{array}{c}\text { Data } \\
\text { ke- }\end{array}$ & $\begin{array}{c}\text { Tegangan } \\
\text { pengukuran } \\
(\mathrm{V})\end{array}$ & $\begin{array}{c}\text { Tegangan } \\
\text { sensor } \\
(\mathrm{V})\end{array}$ & $\begin{array}{c}\text { Deviasi } \\
(\mathrm{V})\end{array}$ \\
\hline 1 & 9,43 & 9,78 & 0,35 \\
2 & 10,58 & 10,8 & 0,22 \\
3 & 11,31 & 11,53 & 0,22 \\
4 & 12,2 & 12,4 & 0,2 \\
5 & 13,27 & 13,4 & 0,13 \\
6 & 14,63 & 14,8 & 0,17 \\
7 & 15,65 & 15,8 & 0,15 \\
8 & 16,11 & 16,24 & 0,13 \\
9 & 17,63 & 17,8 & 0,17 \\
10 & 18,01 & 18,3 & 0,29 \\
\hline
\end{tabular}

Berdasarkan Tabel 1, nilai deviasi rata-rata pembacaan tegangan pengukuran dan tegangan hasil pembacaan sensor adalah 0,203 volt.

\subsubsection{Pengujian Sensor Arus}

Tujuan dari pengujian sensor arus adalah untuk membandingkan hasil pembacaan sensor arus hasil perancangan dengan hasil pembacaan arus menggunakan Multimeter Dekko DM133D
Tabel 2. Perbandingan arus hasil pengukuran dengan sensor arus

\begin{tabular}{ccccc}
\hline $\begin{array}{c}\text { Duty } \\
\text { Cycle } \\
(\%)\end{array}$ & $\begin{array}{c}\text { Beban } \\
(\Omega)\end{array}$ & $\begin{array}{c}\text { Arus tangampere } \\
(\mathrm{A})\end{array}$ & $\begin{array}{c}\text { Arus } \\
\text { sensor } \\
(\mathrm{A})\end{array}$ & $\begin{array}{c}\text { Deviasi } \\
(\mathrm{A})\end{array}$ \\
\hline 10 & 22 & 0,06 & 0,07 & 0,01 \\
20 & 22 & 0,16 & 0,15 & 0,01 \\
25 & 22 & 0,22 & 0,23 & 0,01 \\
30 & 22 & 0,29 & 0,29 & 0 \\
35 & 22 & 0,37 & 0,37 & 0 \\
40 & 22 & 0,46 & 0,44 & 0,02 \\
45 & 22 & 0,55 & 0,51 & 0,04 \\
50 & 22 & 0,67 & 0,66 & 0,01 \\
55 & 22 & 0,81 & 0,81 & 0 \\
\hline
\end{tabular}

Berdasarkan Tabel 2, nilai deviasi rata-rata pembacaan arus pengukuran dan arus hasil pembacaan sensor adalah 0,011 volt.

\subsection{Pengujian Rangkaian Konverter Arus Searah Zeta}

Pengujian rangkaian konverter Zeta terdiri dari pengujian tegangan keluaran konverter Zeta dengan umpan balik tegangan dan pengujian arus keluaran konverter Zeta dengan umpan balik.

\subsubsection{Pengujian Rangkaian Konverter Zetadengan Umpan Balik Tegangan}

Pengujian rangkaian konverter Zeta dengan umpan balik tegangan dilakukan dengan cara menghubungkan keluaran konverter Zeta dengan rangkaian pembagi tegangan (sensor tegangan), kemudian output dari rangkaian pembagi tegangan diumpan balikkan ke Arduino Nano, sehingga rangkaian konverter Zeta dalam kondisi closed loop. Pada Gambar 7. tersaji gambar rangkaian konverter Zeta dengan umpan balik tegangan sebagai berikut:

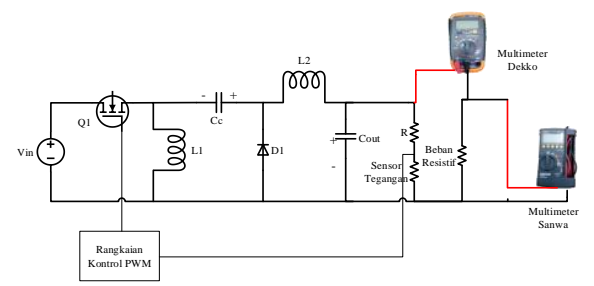

Gambar 7. Rangkaian konverter Zeta dengan umpan balik tegangan

Berikut tersaji data pengujian rangkaian konverter Zeta dengan umpan balik tegangan pada Tabel 3 di bawah ini. 
Tabel 3. Pengujian rangkaian konverter Zeta dengan umpan balik tegangan

\begin{tabular}{|c|c|c|c|c|c|}
\hline Duty Cycle & $V_{\mathbb{I N}}$ & $\mathrm{I}_{\mathrm{N}}$ & VoUt & lout & Beban \\
\hline (\%) & $(\mathrm{V})$ & (A) & (V) & (A) & $(\Omega)$ \\
\hline 45,2 & 17,58 & 0,28 & 13,48 & 0,32 & 39 \\
\hline 45,2 & 17,6 & 0,24 & 13,61 & 0,27 & 47 \\
\hline 44 & 17,68 & 0,19 & 13,53 & 0,21 & 57 \\
\hline 43,8 & 17,89 & 0,17 & 13,57 & 0,18 & 68 \\
\hline 43,8 & 17,75 & 0,17 & 13,5 & 0,16 & 78 \\
\hline 43,8 & 17,8 & 0,14 & 13,52 & 0,15 & 82 \\
\hline 43,8 & 17,78 & 0,11 & 13,51 & 0,13 & 95 \\
\hline 43,8 & 17,85 & 0,10 & 13,5 & 0,11 & 109 \\
\hline 43,8 & 17,85 & 0,09 & 13,56 & 0,10 & 120 \\
\hline 43,8 & 17,83 & 0,07 & 13,65 & 0,08 & 139 \\
\hline
\end{tabular}

Berdasarkan Tabel 3, terlihat bahwa nilai tegangan output dari konverter Zeta untuk nilai setpoint tegangan sebesar 13,5 volt. Nilai 13,5 V dipilih karena tegangan tersebut digunakan untuk pengisian akumulator pada fase float charge. Percobaan umpan balik tegangan dilakukan pada variasi beban menggunakan resistor batu dengan daya 5 Watt. Nilai tegangan output mengalami perbedaan pada variasi beban, hal tersebut disebabkan karena adanya osilasi tegangan keluaran, akan tetapi nilai dari tegangan keluaran masih mendekati nilai setpoint yang diinginkan.

\subsubsection{Pengujian Rangkaian Konverter Zeta dengan Umpan Balik Arus}

Pengujian rangkaian konverter Zeta dengan umpan balik arus dilakukan dengan cara menghubungkan keluaran positif dari konverter Zeta ke sensor arus, kemudian keluaran positif dihubungkan dengan beban. Pada Gambar 8. tersaji gambar rangkaian konverter Zeta dengan umpan balik arus sebagai berikut:

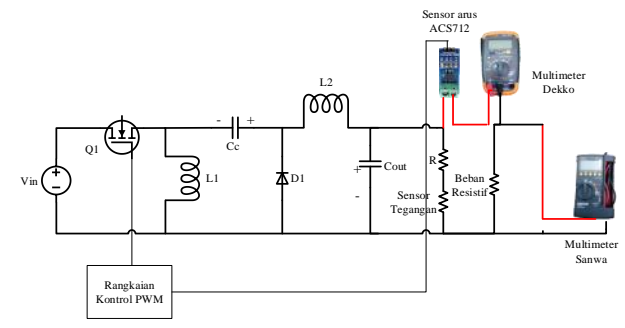

Gambar 8. Rangkaian konverter Zeta dengan umpan balik arus

Berikut tersaji data pengujian rangkaian konverter Zeta dengan umpan balik arus pada Tabel 4 di bawah ini.

Berdasarkan Tabel 4, terlihat bahwa nilai tegangan output dari konverter Zeta untuk nilai setpoint arus sebesar 0,1 A. Percobaan umpan balik arus dilakukan pada variasi beban menggunakan resistor batu $10 \Omega 5 \mathrm{~W}$. Nilai arus output mengalami perbedaan pada variasi beban, hal tersebut disebabkan karena adanya osilasi arus keluaran, akan tetapi nilai dari arus keluaran masih mendekati nilai setpoint yang diinginkan.

Tabel 4. Pengujian rangkaian konverter Zeta dengan umpan balik arus

\begin{tabular}{cccccc}
\hline $\begin{array}{c}\text { Duty Cycle } \\
(\%)\end{array}$ & $\begin{array}{c}\mathrm{V}_{\text {IN }} \\
(\mathrm{V})\end{array}$ & $\begin{array}{c}\mathrm{I}_{\mathrm{IN}} \\
(\mathrm{A})\end{array}$ & $\begin{array}{c}\mathrm{V}_{\text {OUT }} \\
(\mathrm{V})\end{array}$ & $\begin{array}{c}\text { loUT } \\
(\mathrm{A})\end{array}$ & $\begin{array}{c}\text { Beban } \\
(\Omega)\end{array}$ \\
\hline 19,6 & 18,38 & 0,06 & 4,53 & 0,1 & 27 \\
24,8 & 18,36 & 0,06 & 5,34 & 0,12 & 39 \\
27,9 & 18,02 & 0,05 & 6,6 & 0,11 & 47 \\
37,2 & 18,12 & 0,12 & 7,84 & 0,14 & 57 \\
33,3 & 17,99 & 0,06 & 8,87 & 0,12 & 68 \\
30,6 & 18,06 & 0,1 & 7,63 & 0,08 & 78 \\
30,6 & 18,15 & 0,07 & 6,35 & 0,08 & 82 \\
33,3 & 18,12 & 0,08 & 10,2 & 0,08 & 95 \\
38,8 & 18,1 & 0,08 & 11,63 & 0,1 & 100 \\
\hline
\end{tabular}

\subsection{Pengujian Pengisian Akumulator}

Berikut tersaji data pengujian pengisian akumulator pada Tabel 5 di bawah ini.

Tabel 5. Data pengujian pengisian akumulator

\begin{tabular}{cccc}
\hline Menit ke- & Duty Cycle $(\%)$ & $\begin{array}{c}\text { Arus } \\
(\mathrm{A})\end{array}$ & $\begin{array}{c}\text { Tegangan } \\
(\mathrm{V})\end{array}$ \\
\hline 0 & 42,8 & 0,24 & 12,04 \\
30 & 42,8 & 0,22 & 12,42 \\
60 & 42,8 & 0,24 & 12,56 \\
90 & 42,8 & 0,25 & 12,58 \\
210 & 42,8 & 0,24 & 12,63 \\
330 & 42,8 & 0,25 & 12,71 \\
570 & 42,8 & 0,24 & 12,84 \\
690 & 42,8 & 0,24 & 12,89 \\
750 & 42,8 & 0,24 & 12,91 \\
960 & 42,8 & 0,23 & 13,14 \\
1020 & 42,8 & 0,22 & 13,25 \\
1140 & 42,8 & 0,22 & 13,38 \\
1290 & 42,8 & 0,22 & 13,65 \\
1440 & 42,8 & 0,22 & 13,99 \\
1530 & 42,8 & 0,22 & 14,40 \\
1590 & 43,6 & 0,30 & 14,56 \\
1650 & 43,0 & 0,27 & 14,45 \\
1710 & 42,4 & 0,09 & 13,65 \\
1770 & 42,4 & 0,08 & 13,57 \\
\hline
\end{tabular}

Berdasarkan Tabel 5 diatas dapat dilihat nilai arus yang digunakan saat fase bulk charge adalah berkisar antara 0,22 sampai 0,25 A, kemudian saat fase absorption charge nilai tegangan dijaga pada 14,4 volt, dan saat memasuki fase float charge nilai tegangan diubah menjadi 13.5 volt. Proses pengujian pengisian akumulator dilakukan selama 1770. Proses pengisian akumulator dihentikan saat memasuki fase float charge.

\section{Kesimpulan}

Berdasarkan perancangan, pengujian, dan analisis yang telah dilakukan, maka dapat disimpulkan bahwa nilai tegangan keluaran dapat dijaga konstan sebesar 13,5 V dengan deviasi rata-rata 0,047 volt. Nilai tegangan keluaran dijaga konstan untuk beban berupa resistansi murni dengan nilai $39 \Omega, 47 \Omega, 57 \Omega, 68 \Omega, 78 \Omega, 82 \Omega$, 
$95 \Omega, 109 \Omega, 120 \Omega$, dan $139 \Omega$. Nilai efisiensi rata-rata rangkaian konverter arus searah tipe Zeta dengan umpan balik tegangan adalah sebesar $83,74 \%$. Sedangkan untuk pengujian dengan umpan balik arus, nilai arus keluaran dapat dijaga konstan sebesar 0,1 A dengan deviasi ratarata sebesar 0,015 A. Nilai arus keluaran dijaga konstan untuk beban berupa resistansi murni dengan nilai $27 \Omega$, $39 \Omega, 47 \Omega, 57 \Omega, 68 \Omega, 78 \Omega, 82 \Omega, 95 \Omega$, dan $100 \Omega$. Pada pengujian pengisian akumulator, nilai arus dapat dijaga konstan pada fase bulk charge sebesar 0,25 A, sedangkan pada fase absortion charge nilai tegangan dapat dijaga konstan 14,4 volt dan saat float charge nilai tegangan dapat dijaga konstan sebesar 13,5 volt.

\section{Referensi}

[1]. Blueprint Pengelolaan Energi Nasional 2006-2025, Kementerian Energi dan Sumber Daya Mineral, 2007.

[2]. J. Falin, "Designing DC/DC converters based on ZETA topology," Texas Instruments Incorporated, Texas, 2010.
[3]. A. P. Nandiwardhana, H. Suryoatmojo and d. M. Ashari, "Perancangan Zeta Converter yang dilengkapi Power Factor Correction pada Aplikasi Pengaturan Kecepatan Motor Brushless DC," JURNAL TEKNIK ITS, vol. 5, 2016.

[4]. E.S.D. Prakoso, T. Andromeda and B. Winardi, "Perancangan Konverter Arus Searah Zeta Voltage Feedback Menggunakan IC T1494" TRANSIENT, 2017.

[5]. A. M. Jainudin, A. Warsito and T. Andromeda, "Konverter Arus Searah Tipe Buck Dengan Umpan Balik Arus dan Tegangan Untuk Pengisi Akumulator," TRANSIENT, 2017

[6]. H. Y. Yong, N. I. Rusli, and M. F. N. Tajuddin, "Output Voltage Control of Dual Input Single Ended Primary Inductor Converter (SEPIC) for Hybrid Photovoltaic and Piezoelectric System," IEEE, 2017, pp. 349-354

[7]. Power MOSFET IRFZ44N, International Rectifier.

[8]. Schottky Barrier Rectifier, Rectron Semiconductor.

[9]. TLP250, Toshiba, 2004. 